\title{
BMJ Open Identifying patients with psychosocial problems in general practice: a scoping review protocol
}

\author{
Rosemarie Schwenker (D) , ${ }^{1}$ Eric Sven Kroeber (D) , ${ }^{1}$ Tobias Deutsch (D) , \\ Thomas Frese, ${ }^{1}$ Susanne Unverzagt (i) ${ }^{1}$
}

To cite: Schwenker R, Kroeber ES, Deutsch T, et al. Identifying patients with psychosocial problems in general practice: a scoping review protocol. BMJ Open 2021;11:e051383. doi:10.1136/ bmjopen-2021-051383

- Prepublication history and additional supplemental material for this paper are available online. To view these files, please visit the journal online (http://dx.doi.org/10.1136/ bmjopen-2021-051383).

Received 17 March 2021 Accepted 05 November 2021

Check for updates

(c) Author(s) (or their employer(s)) 2021. Re-use permitted under CC BY-NC. No commercial re-use. See rights and permissions. Published by BMJ.

${ }^{1}$ Faculty of Medicine, Institute of General Practice and Family Medicine, Center of Health Sciences, Martin Luther University of Halle Wittenberg, Halle (Saale), Germany

${ }^{2}$ Department of General Practice, Faculty of Medicine, University of Leipzig, Leipzig, Germany

Correspondence to Rosemarie Schwenker; rosemarie.schwenker@ukhalle.de

\section{ABSTRACT}

Introduction Psychosocial problems (PSPs) are common issues associated with negative health outcomes. Since general practitioners are the first point of contact for any health-related concern, understanding their options to recognise patients with PSPs plays an important role as it is essential for early intervention and can prevent serious conditions. The objective of our scoping review is to map published evidence on the usage of instruments to identify patients with PSPs in general practice.

Methods and analysis We will follow the Preferred Reporting Items for Systematic Reviews and MetaAnalyses extension for Scoping Reviews checklist and the Joanna Briggs Institute Reviewer's Manual on scoping reviews. A systematic search of four electronic databases (Medline (Ovid), Web of Science Core Collection, Psyclnfo, Cochrane Library) will be conducted for quantitative and qualitative studies published in English, Spanish, French and German. Main study characteristics as well as information on identification instruments will be extracted and visualised in structured tables to map the available evidence. The protocol has been registered with Open Science Framework, https://osfio/c2m6z.

Ethics and dissemination This study does not require ethical approval as we will not collect personal data. Dissemination will consist of publications, presentations and other knowledge translation activities.

\section{BACKGROUND}

Since general practitioners (GPs) are the first point of contact for people with any healthrelated concern, patients visit their GP not only for medical reasons but also for psychosocial problems (PSPs). ${ }^{1-3}$ This issue was started to be studied decades ago ${ }^{4-6}$ and a vast body of research has investigated the significance of PSPs in health. People with PSPs are vulnerable to negative health outcomes, comorbidities and show a generally poorer health status. ${ }^{7}$ PSPs affect immunologic and inflammatory processes ${ }^{8-10}$ and are associated with an increased risk of illness, delayed recovery, chronic disease progression, compromised quality of life and mortality rates. ${ }^{7}$ 11-13 Individuals who are socially isolated are at risk of premature mortality,

\section{Strengths and limitations of this study}

- Our review addresses a topic of great public health importance, as early and structured identification of patients with psychosocial problems (PSPs) in general practice can improve patient health, the work of primary care professionals and the healthcare system.

- This will be the first scoping review to analyse which instruments general practitioners use to identify patients with PSPS.

- The search strategy includes four electronic databases with peer-reviewed literature and is based on tailored search strings which have been iteratively refined in order to retrieve as many relevant published studies as possible.

- A limitation of our scoping review will be that a quality and risk of bias assessment of the included studies will not be performed.

comparable to well-documented risk factors, such as smoking and obesity. ${ }^{14-18}$ Certain work factor combinations increase health impairments. ${ }^{19-21}$ PSPs are related to several conditions, such as cardiovascular diseases, diabetes, infectious diseases and psychiatric disorders. ${ }^{1722-27}$

Studies show that at least one-third of patients in general practices report suffering from PSPs. GPs in Germany are consulted by patients with PSPs at least three times a week. ${ }^{3} 2829$ Major problems identified were family problems, caregiving tasks, violencerelated issues, isolation, financial problems, employment problems, problems with physical functioning and legal problems. ${ }^{3} 46$ 60-38 The International Classification of Primary Care, second edition (ICPC-2) includes a section that captures the most common social problems encountered in the primary care context ${ }^{39}$ which we include in our understanding of PSPs as we intend to focus on these kinds of problems that do not yet meet the criteria for a psychological or psychiatric diagnosis and for medical treatment. Studies 
Table 1 Inclusion and exclusion criteria for eligible studies

\begin{tabular}{|c|c|c|}
\hline & Inclusion & Exclusion \\
\hline Population & $\begin{array}{l}\text { Adolescent or adult patients in general practices, } \\
\text { with PSPs in general or specific social problems } \\
(\text { eg, social problems according to ICPC-2, Section } \\
\text { Z) }\end{array}$ & $\begin{array}{l}\text { Patients with disease-specific PSPs related } \\
\text { to, for example, cancer, HIV, diabetes, } \\
\text { substance use disorder or psychiatric } \\
\text { disorders }\end{array}$ \\
\hline Concept & $\begin{array}{l}\text { Any kind of identification instrument (eg, } \\
\text { questionnaire, interview) and reporting formats } \\
\text { (eg, self-reported, clinical examination) for PSPs }\end{array}$ & \\
\hline Type of studies & $\begin{array}{l}\text { Quantitative study designs (eg, cross-sectional } \\
\text { studies, cohort studies, case-control studies), } \\
\text { qualitative studies, mixed methods studies }\end{array}$ & $\begin{array}{l}\text { Study protocols } \\
\text { Reviews } \\
\text { - Author replies/comments }\end{array}$ \\
\hline
\end{tabular}

${ }^{*}$ Poverty/financial problem (Z01), Food/water problem (ZO2), Housing/neighborhood problem (ZO3), Social cultural problem (ZO4), Work problem (Z05), Unemployment problem (Z06), Education problem (Z07), Social welfare problem (Z08), Legal problem (Z09), Health care system problem (Z10), Compliance/being ill problem (Z11), Relationship problem with partner (Z12), Partner's behavior problem (Z13), Partner illness problem (Z14), Loss/death of partner problem (Z15), Relationship problem with child (Z16), Illness problem with child (Z18), Loss/death of child problem (Z19), Relationship problem parent/family (Z20), Behavior problem parent/family (Z21), Illness problem parent/family (Z22), Loss/death parent/family member (Z23), Relationship problem friend (Z24), Assault/harmful event problem (Z25), Fear of a social problem (Z27) and Limited function/disability (Z28).

EQUATOR, enhancing the quality and transparency of health research; ICPC-2, international classification of primary care, second edition; PSPs, psychosocial problems.

also show that GPs recognise a fifth to a half of patients with relevant PSPs, ${ }^{5}$ which can lead to inadequate diagnostics, non-specific or no intervention or treatment at all and ineffective use of time. ${ }^{2432} 33353640-48$

Although integration of the psychosocial perspective into medicine is widely demanded in research and from official health organisations, a practical approach in the form of a systematic and structured instrument is not part of the recommendations and is therefore worth investigating. ${ }^{1} 744$ 49-51

Health complaints related to PSPs that are not primarily medical and that do not yet have the status of a disease or disorder are inherently complex and heterogeneous. Providing or referring to a universally valid concept of PSPs is difficult as academic disciplines, as well as organisations outside the academic context and policy-makers use different concepts. Nevertheless, PSPs are a relevant issue in everyday general practice and structured approaches could help provide guidance to GPs and their practice team early in the continuum of care. Early identification of problems will help to better meet patient needs and GPs resources. Against this background, we are particularly interested in instruments that are supportive and practical in daily practice and that capture a broad range of PSPs at once. Existing screening tools (eg,
General Health Questionnaire, Somatic and Psychological Health Report Questionnaire $)^{52-54}$ show an acceptable validity and reliability, but are not regularly used in general practice.

The aim of our scoping review is to comprehensively explore the evidence on instruments that can help GPs and their practice team identify patients with PSPs and thus contribute to the development of a practical approach that incorporates the biopsychosocial perspective in medicine. Bringing the results together will help provide an overview of the evidence and identify knowledge gaps, which will provide direction for further research activities.

Our research question is: What is known about the usage of instruments to identify patients with PSPs in general practice?

To our knowledge, there is no scoping review that addresses the question proposed by this review.

\section{METHODS AND ANALYSIS}

The scoping review will be conducted by following the Preferred Reporting Items for Systematic Reviews and Meta-Analyses extension for Scoping Reviews (PRISMA-ScR) checklist ${ }^{55}$ and the Joanna Briggs Institute 


\begin{tabular}{|c|c|}
\hline \multirow{9}{*}{$\begin{array}{l}\text { General } \\
\text { information }\end{array}$} & Study name \\
\hline & References of the publication(s) \\
\hline & Objective(s) as stated \\
\hline & Study design as described \\
\hline & Years of study execution \\
\hline & $\begin{array}{l}\text { Sample size of included and analysed } \\
\text { participants or practices }\end{array}$ \\
\hline & $\begin{array}{l}\text { Definition of PSPs as described (with } \\
\text { reference) }\end{array}$ \\
\hline & Components of PSPs examined \\
\hline & $\begin{array}{l}\text { Prevalence of patients with PSPs reported } \\
\text { (eg, number of patients per week/month/ } \\
\text { year or study period) }\end{array}$ \\
\hline \multirow[t]{5}{*}{ Population } & Age (years) \\
\hline & Gender \\
\hline & Ethnicity \\
\hline & $\begin{array}{l}\text { Specific characteristics (eg, geriatric } \\
\text { patients, pregnant women) }\end{array}$ \\
\hline & Other comorbidities \\
\hline \multirow[t]{2}{*}{ Context } & Country of origin \\
\hline & General practice setting \\
\hline \multirow[t]{9}{*}{ Concept } & $\begin{array}{l}\text { Name of identification instrument with } \\
\text { reference }\end{array}$ \\
\hline & $\begin{array}{l}\text { Type of identification instrument (eg, } \\
\text { questionnaire, interview) }\end{array}$ \\
\hline & Description of identification instrument \\
\hline & $\begin{array}{l}\text { Type of reporting format (eg, self-reported, } \\
\text { clinical examination) }\end{array}$ \\
\hline & $\begin{array}{l}\text { Identification instrument administered } \\
\text { (eg, by physician, nurse, patient, other } \\
\text { professionals) }\end{array}$ \\
\hline & Time to complete (min) \\
\hline & $\begin{array}{l}\text { Components examined (eg, social factors, } \\
\text { environmental factors) }\end{array}$ \\
\hline & $\begin{array}{l}\text { Identification instrument scored (eg, by } \\
\text { physician, nurse, patient) }\end{array}$ \\
\hline & Conclusion stated by authors \\
\hline
\end{tabular}

PSPs, psychosocial problems.

(JBI) Reviewer's Manual on scoping reviews. ${ }^{56}$ Due to the various study types, diverse definitions of PSPs, as well as identification instruments, heterogeneity across studies is expected to be high. Therefore, a scoping review was chosen as an appropriate approach. ${ }^{5758}$

\section{Eligibility criteria}

Studies will be eligible for inclusion if they meet the specified criteria presented in table 1 .

Included studies are required (1) to include adolescent or adult patients in general practices and (2) to use any kind of instrument or format to identify patients with
PSPs. We take into consideration studies that include PSPs in general as well as studies that focus on specific social problems according to the ICPC-2. ${ }^{39}$ We will include studies with samples from all countries. Studies will be excluded if the study population consists of patients with PSPs related to specific chronic diseases or conditions (eg, cancer, HIV, diabetes, substance use disorder or psychiatric disorders), as it can be assumed that GPs are more likely to ask about PSPs if they know of an existing disease. In line with the characteristics of a scoping review, this review will consider not only quantitative study designs for inclusion (eg, cohort studies, case-control studies and cross-sectional studies) but also qualitative studies and mixed methods studies. We will include full-text publications in English, Spanish, French and German without time restrictions.

\section{Information sources and search strategy}

We developed a search strategy for Medline (Ovid) (see table 1 in the online supplemental file 1) and will adapt this strategy to the databases PsycInfo, the Cochrane Library and the Web of Science Core Collection. We will hand search and screen reference lists of included studies to identify other potential studies that meet the inclusion criteria. We will screen the reference lists of systematic reviews and scoping reviews which examined studies potentially fitting our inclusion criteria for further relevant studies. Search results will be downloaded and imported into the reference management tool EndNote X9. After elimination of duplicates, the remaining references will be uploaded and screened in Rayyan. ${ }^{59}$

\section{Study selection process}

With our research team consisting of a sociologist, a psychologist, a general practitioner, a physician and a methodologist, we follow the multidisciplinary team approach as proposed by Levac et $a l^{60}$ In the first step of selection process, two reviewers will independently screen titles and abstracts and select studies that meet the inclusion criteria (table 1). This step is followed by full-text screening of these potentially relevant studies. Disagreements will be solved by discussion between the two reviewers until consensus is obtained or a third reviewer will be consulted. The process of study selection will be presented in a PRISMA flow chart, including the results from the search, elimination of duplicates, phases of studies selection, reasons for exclusion after full-text read and final number of included studies. We will provide a list of all potentially relevant studies that were read in fulltext form, but excluded from the review and justify the exclusion.

\section{Data extraction process}

A data extraction form has been developed specifically for this scoping review (table 2). Data extraction will be piloted on five studies by two independent reviewers and the form modified if necessary. Afterwards, two reviewers will independently extract data from selected studies. 
Any discussion between the reviewers will be resolved by discussion or a third reviewer will be consulted. If study results are reported in more than one publication, we will summarise the information of both publications. In case of conflicting results, the first full-text publication will be the main data source.

The extraction form contains detailed information on subjects provided in table 2 .

A quality and risk of bias assessment of the included studies will not be performed as this is not the aim of a scoping review. ${ }^{56} 58$

\section{Collating, summarising and reporting data}

Our search results will be reported by using a flow diagram to clearly detail the review decision process. We will map the characteristics of the included studies and the evidence found on different identification instruments in a structured tabular form. A clear narrative summary related to the objective of the scoping review will follow. Aggregated findings will provide an overview of the research that has been conducted on the use of instruments to identify patients with PSPs in general practice, highlight knowledge gaps and inform the direction of further research activities.

\section{Patient and public involvement}

No patients or public were involved in the development of this protocol.

\section{ETHICS AND DISSEMINATION}

As we will synthesise information from publicly available publications and will not collect personal, sensitive or confidential information from participants, ethical approval is not required. Dissemination activities will consist of reporting results of the scoping review by submitting an article for publication to a scientific journal and presenting results at relevant conferences.

Contributors RS developed the concept, inclusion criteria and search strategy, wrote the draft and revision of this protocol and submitted the protocol. ESK contributed to the development of the concept, critically read and commented on the draft and provided expertise from a medical perspective. TD contributed to the inclusion criteria and critically read and commented on the draft. TF critically read and commented on the draft and provided expertise from primary care. SU has expertise in systematic reviews and is the guarantor of the methodological quality of this scoping review and contributed to the development of the concept, search strategy and the draft.

Funding The authors have not declared a specific grant for this research from any funding agency in the public, commercial or not-for-profit sectors.

Competing interests None declared.

Patient consent for publication Not applicable.

Provenance and peer review Not commissioned; externally peer reviewed.

Supplemental material This content has been supplied by the author(s). It has not been vetted by BMJ Publishing Group Limited (BMJ) and may not have been peer-reviewed. Any opinions or recommendations discussed are solely those of the author(s) and are not endorsed by BMJ. BMJ disclaims all liability and responsibility arising from any reliance placed on the content. Where the content includes any translated material, BMJ does not warrant the accuracy and reliability of the translations (including but not limited to local regulations, clinical guidelines, terminology, drug names and drug dosages), and is not responsible for any error and/or omissions arising from translation and adaptation or otherwise.

Open access This is an open access article distributed in accordance with the Creative Commons Attribution Non Commercial (CC BY-NC 4.0) license, which permits others to distribute, remix, adapt, build upon this work non-commercially, and license their derivative works on different terms, provided the original work is properly cited, appropriate credit is given, any changes made indicated, and the use is non-commercial. See: http://creativecommons.org/licenses/by-nc/4.0/.

ORCID iDs

Rosemarie Schwenker http://orcid.org/0000-0001-6382-8583

Eric Sven Kroeber http://orcid.org/0000-0002-7201-6023

Tobias Deutsch http://orcid.org/0000-0002-0936-6282

Susanne Unverzagt http://orcid.org/0000-0002-0108-0415

\section{REFERENCES}

1 Deutsche Gesellschaft für Allgemeinmedizin und Familienmedizin. DEGAM-Zukunftspositionen: Allgemeinmedizin-Spezialisiert auf den ganzen. Menschen, 2013. https://www.degam.de/files/ Inhalte/Degam-Inhalte/Ueber_uns/Positionspapiere/DEGAM_ Zukunftspositionen.pdf

2 Hartmann M, Finkenzeller C, Boehlen FH. Psychosomatische Sprechstunde in Der Hausarztpraxis-ein neues Kooperationsmodell von Psychosomatik und Allgemeinmedizin. Balint Journal 2018:19:116-20.

3 Zimmermann T, Mews C, Kloppe T, et al. [Social problems in primary health care - prevalence, responses, course of action, and the need for support from a general practitioners' point of view]. Z Evid Fortbild Qual Gesundhwes 2018;131-132:81-9.

4 Gulbrandsen P, Hjortdahl P, Fugelli P. General practitioners' knowledge of their patients' psychosocial problems: multipractice questionnaire survey. BMJ 1997;314:1014-8.

5 Huibers MJ, Beurskens A, Bleijenberg G. Psychosocial interventions delivered by general practitioners. Cochrane Database of Systematic Reviews 2003;2.

6 Zantinge EM, Verhaak PFM, Bensing JM. The workload of GPs: patients with psychological and somatic problems compared. Fam Pract 2005;22:293-7.

7 Institute of Medicine. Committee on health practice policy. In: Health and behavior: the interplay of biological, behavioral, and societal influences. National Academies Press, 2001.

8 Segerstrom SC, Miller GE. Psychological stress and the human immune system: a meta-analytic study of 30 years of inquiry. Psychol Bull 2004;130:601.

9 Furman D, Campisi J, Verdin E, et al. Chronic inflammation in the etiology of disease across the life span. Nat Med 2019;25:1822-32.

10 Hänsel A, Hong S, Cámara RJA, et al. Inflammation as a psychophysiological biomarker in chronic psychosocial stress. Neurosci Biobehav Rev 2010;35:115-21.

11 Krantz DS, McCeney MK. Effects of psychological and social factors on organic disease: a critical assessment of research on coronary heart disease. Annu Rev Psychol 2002;53:341-69.

12 Kuper H, Marmot M, Hemingway H. Systematic review of prospective cohort studies of psychosocial factors in the etiology and prognosis of coronary heart disease. Semin Vasc Med 2002;2:267-314.

13 Hemingway H, Marmot M. Evidence based cardiology: psychosocial factors in the aetiology and prognosis of coronary heart disease. systematic review of prospective cohort studies. BMJ 1999;318:1460-7.

14 Holt-Lunstad J, Smith TB, Baker M, et al. Loneliness and social isolation as risk factors for mortality: a meta-analytic review. Perspect Psychol Sci 2015;10:227-37.

15 Pantell M, Rehkopf D, Jutte D, et al. Social isolation: a predictor of mortality comparable to traditional clinical risk factors. Am J Public Health 2013;103:2056-62.

16 Beller J, Wagner A. Loneliness, social isolation, their synergistic interaction, and mortality. Health Psychol 2018;37:808-13.

17 Hakulinen C, Pulkki-Råback L, Virtanen M, et al. Social isolation and loneliness as risk factors for myocardial infarction, stroke and mortality: UK Biobank cohort study of 479054 men and women. Heart 2018;104:1536-42.

18 Holt-Lunstad J. The potential public health relevance of social isolation and loneliness: prevalence, epidemiology, and risk factors. Public Policy Aging Report 2017;27:127-30.

19 Amick BC, McDonough P, Chang $\mathrm{H}$, et al. Relationship between allcause mortality and cumulative working life course psychosocial and 
physical exposures in the United States labor market from 1968 to 1992. Psychosom Med 2002;64:370-81.

20 Shirom A, Toker S, Alkaly Y, et al. Work-based predictors of mortality: a 20-year follow-up of healthy employees. Health Psychol 2011;30:268

21 Niedhammer I, Milner A, Coutrot T, et al. Psychosocial work factors of the job strain model and all-cause mortality: the STRESSJEM prospective cohort study. Psychosom Med 2021;83:62-70.

22 Kivimäki M, Steptoe A. Effects of stress on the development and progression of cardiovascular disease. Nat Rev Cardiol 2018;15:215.

23 Everson-Rose SA, Lewis TT. Psychosocial factors and cardiovascular diseases. Annu Rev Public Health 2005;26:469-500.

24 Hackett RA, Steptoe A. Psychosocial factors in diabetes and cardiovascular risk. Curr Cardiol Rep 2016;18:95.

25 Hamer M, Kivimaki M, Stamatakis E, et al. Psychological distress and infectious disease mortality in the general population. Brain Behav Immun 2019;76:280-3.

26 Cohen S, Tyrrell DAJ, Smith AP. Psychological stress and susceptibility to the common cold. N Engl J Med Overseas Ed 1991;325:606-12.

27 Cohen S. Psychosocial vulnerabilities to upper respiratory infectious illness: implications for susceptibility to coronavirus disease 2019 (COVID-19). Perspect Psychol Sci 2021:16:161-74.

28 Del Piccolo L, Saltini A, Zimmermann C. Which patients talk about stressful life events and social problems to the general practitioner? Psychol Med 1998;28:1289-99.

29 Gulbrandsen P, Fugelli P, Sandvik L, et al. Influence of social problems on management in general practice: multipractice questionnaire survey. BMJ 1998;317:28-32.

30 Fritzsche K, Sandholzer H, Werner J. Psychotherapeutische und psychosoziale Behandlungsmaßnahmen in Der Hausarztpraxis. PPmP-Psychotherapie. Psychosomatik. Medizinische Psychologie 2000;50:240-6.

31 Grayer J, Cape J, Orpwood L, et al. Facilitating access to voluntary and community services for patients with psychosocial problems: a before-after evaluation. BMC Fam Pract 2008;9:27.

32 Jobst D, Joos S. Soziale Patientenanliegen-eine Erhebung in Hausarztpraxen. Z Allg Med 2014;90:496-501.

33 Laux G, Kühlein T, Gutscher A. Versorgungsforschung in Der Hausarztpraxis. München: Urban und Vogel, 2010.

34 Popay J, Kowarzik U, Mallinson S, et al. Social problems, primary care and pathways to help and support: addressing health inequalities at the individual level. Part I: the GP perspective. $J$ Epidemiol Community Health 2007;61:966-71.

35 Van Hook MP. Psychosocial issues within primary health care settings: challenges and opportunities for social work practice. Soc Work Health Care 2004;38:63-80.

36 Vannieuwenborg L, Buntinx F, De Lepeleire J. Presenting prevalence and management of psychosocial problems in primary care in Flanders. Arch Public Health 2015;73:1-6.

37 Wilfer T, Braungardt T, Schneider W. Soziale Probleme in Der hausärztlichen praxis. Zeitschrift für Psychosomatische Medizin und Psychotherapie 2018;64:250-61.

38 Bikson K, McGuire J, Blue-Howells J, et al. Psychosocial problems in primary care: patient and provider perceptions. Soc Work Health Care 2009:48:736-49.

39 Wonca International Classification Committee (WICC). International classification of primary care. 2 edn, 2021. https://ehelse.no/ kodeverk/icpc-2e-english-version/_/attachment/download/56f8d2b7803c-46dc-84cd-0b4838eba605:b1b6ccf719152365ab9668c45fb5 d0aced197038/ICPC-2e-English.pdf

40 Larisch A, Fisch V, Fritzsche K. Kosten-Nutzen-Aspekte psychosozialer Interventionen bei somatisierenden Patienten in Der Hausarztpraxis. Zeitschrift für Klinische Psychologie und Psychotherapie 2005;34:282-90.
41 Vázquez-Barquero JL, García J, Simón JA, et al. Mental health in primary care. An epidemiological study of morbidity and use of health resources. Br J Psychiatry 1997;170:529.

42 Zimmermann C, Tansella M. Psychosocial factors and physical illness in primary care: promoting the biopsychosocial model in medical practice. J Psychosom Res 1996;40:351-8.

43 Huibers MJH, Beurskens AJHM, Bleijenberg G, et al. Psychosocial interventions by general practitioners. Cochrane Database Syst Rev 2007:CD003494.

44 Fritzsche K, Sandholzer H, Brucks U, et al. Psychosocial care by general practitioners--where are the problems? Results of a demonstration project on quality management in psychosocial primary care. Int J Psychiatry Med 1999;29:395-409.

45 Frese T, Hein S, Sandholzer H. Feasibility, understandability, and usefulness of the step self-rating questionnaire: results of a crosssectional study. Clin Interv Aging 2013;8:515.

46 Deutsche Gesellschaft für Allgemeinmedizin und Familienmedizin, Beschluss Der Jahreshauptversammlung vom 21.9.2002: Deutsche Gesellschaft für Allgemeinmedizin und Familienmedizin, 2002. Available: https://www.degam.de/fachdefinition.html [Accessed 08 Jul 2020].

47 Zantinge EM, Verhaak PFM, Bensing JM. The workload of GPs: patients with psychological and somatic problems compared. Fam Pract 2005;22:293-7.

48 Kendrick T, King F, Albertella L. Gp treatment decisions for patients with depression: an observational study. $\mathrm{Br} J$ Gen Pract 2005;55:280-6.

49 Engert V, Grant JA, Strauss B. Psychosocial factors in disease and Treatment-A call for the biopsychosocial model. JAMA Psychiatry 2020;77:996-7.

50 Mercer SW, Gunn J, Bower P, et al. Managing patients with mental and physical multimorbidity. . British Medical Journal Publishing Group, 2012: 345. e5559.

51 World Health Organization. The world health report 2008: primary health care now more than ever: introduction and overview. World Health Organization, 2008.

52 De la Revilla Ahumada L. De Los Rios Alvarez A, Luna del Castillo J. Use of the Goldberg General Health Questionnaire (GHQ-28) to detect psychosocial problems in the family physician's office. Atencion primaria 2004;33:417-22.

53 McLeod D. General practitioner recognition of mental illness in the absence of a 'gold standard'. Australian and New Zealand Journal of Psychiatry 2004;38:789-94

54 Hickie IB, Davenport TA, Hadzi-Pavlovic D, et al. Development of a simple screening tool for common mental disorders in general practice. Med J Aust 2001;175:S10-17.

55 Tricco AC, Lillie E, Zarin W, et al. PRISMA extension for scoping reviews (PRISMA-ScR): checklist and explanation. Ann Intern Med 2018;169:467-73.

56 Peters MD, Godfrey C, Mclnerney P. Chapter 11: scoping reviews. In: Joanna Briggs Institute Reviewer's Manual. The Joanna Briggs Institute, 2017.

57 Arksey H, O'Malley L. Scoping studies: towards a methodological framework. Int J Soc Res Methodol 2005;8:19-32.

58 Munn Z, Peters MDJ, Stern C, et al. Systematic review or scoping review? guidance for authors when choosing between a systematic or scoping review approach. BMC Med Res Methodol 2018;18:143.

59 Ouzzani M, Hammady H, Fedorowicz Z, et al. Rayyan-a web and mobile APP for systematic reviews. Syst Rev 2016;5:210.

60 Levac D, Colquhoun H, O'Brien KK. Scoping studies: advancing the methodology. Implement Sci 2010;5:69.

61 The EQUATOR Network. Enhancing the quality and transparency of health research: the EQUATOR network, 2021. Available: https:// www.equator-network.org/ [Accessed 04 Feb 2021]. 